on the trunk and limbs "constellations" of vesicles were noted. On the face were observecl papules and a few vesicles. A history was obtained of two previous cases of chicken-pox in the house. The patient had complained of backache and nausea on May 31st but had not been very sick. The temperature when I saw him was normal. There were very few pocks on the scalp and the lesions were more abundant on the upper parts of the limbs than on the lower. The balance of evidence was therefore in favour of a diagnosis of chicken-pox but we were getting sufficiently near the border-line in symptoms to take all due precautions as to isolation of the patient and to urge vaccination or revaccination of contacts.

The above cases in my own experience and the case recorded by Dr. Rolfe recall to my mind that so long ago as $1889 \mathrm{my}$ friend Sir William J. Collins ${ }^{4}$ pointed out that "specificity" depends on the "soil on which the seed is sown; ..... that there is in disease, as in all nature, a tendency of the common to become the specific, the homogeneous to give birth to the heterogeneous." I have made certain observations and deductions in connexion with some other infectious diseases (which I shall record in another place) which all point towards the part played by evolutionary factors in disease processes.

I am, Sirs, yours faithfully,

J. T. C. NASH, M.D. Edin., D.P.H. Cantab.,

Jan. 7th, 1905. Medical Officer of Health, Southend-on-Sea.

\section{THE EVOLUTION OF MAN'S DIET.}

\section{To the Editors of THE LANCET.}

SIRS, - I quite agree with Dr. J. Sim Wallace that we moderns could greatly increase our power to cope with coarse vegetable foods if we from early years accustomed ourselves to them. I believe, however, that even then we should, in respect of this power, fall far below the apes. Not the most primitive race of man could subsist on the natural diet of these creatures, and, though very little anatomical difference can be discovered between the digestive organs of man and the anthropoid, we must, I think, postulate a wide difference in the digestive capabilities of the two. Though the vegetable food of the anthropoids is richer in cellulose than our own, yet even they would appear to avoid as far as possible dense cellulosic substances. Dr. P. C. Mitchell, the able secretary of the London Zoological Society, informs me that the chimpanzee is quite a dainty feeder, not only discarding the skin of the banana but carefully peeling and removing the pips of a choice apple before eating it.

I must doubt whether the bitter, acid, and acrid principles which enter so largely into the natural diet of the anthro. poids facilitate in any substantial degree the digestion of cellulose, but that they may play a useful part in digestion and nutrition, and that the diet of us moderns is all too deficient in them I can well believe. Indeed, I venture to think that here Dr. Wallace makes a most valuable suggestion. There can be no doubt that both man and the apes have an instinctive liking for substances of this kind. Dr. Mitchell finds that when a sick chimpanzee is off its food, and when every other plan has failed, he can incluce the invalid to eat by flavouring its viands with rhubarb ; and we know that children of ten display a violent craving for unripe fruit, in rebellious protest, it would seem, against "the soft, bland, and generally alkaline food" on which they are nowadays nurtured. Whether this bland diet is also, as Dr. Wallace suggests, responsible for their craving for sugar is well worth being put to the test.

$$
\text { I am, Sirs, yours faithfully, }
$$

Wimpole-street, W., Jan. 8th, $1905 . \quad$ HARRY CAMPBELL.

\section{To the Editors of THE LANCET.}

SiRs,-Dr. Harry Campbell's views as to the "evolution of man's diet" must have induced some of your readers to be more particular as to diet in the treatment of disease and so far will do good but the study of diet is a most complex subject and deserving the attention of every member of the profession. It is a subject in which everyone ought to take an interest, since not only the body but the mind depends upon what we put into the stomach. Drugs have dominated

our profession since the days of the alchemists and now there are signs that diet is about to claim more attention, the daily press and the drama having taken it up. From the attention I have been able to give to the subject I am inclined to think that we are suffering from having departed from the diet of primitive man before fire was stolen from the gods and when he ate only fruit and nuts, his natural food. Our food now (apart from the flesh of animals which causes so much disease, directly and indirectly) consists very largely of starch, the conversion of which into dextrine is a great tax on the energy of the digestive system. Good cooking may lessen tine danger of eating such food, but however well cooked our food ought to be masticated thoroughly and kept in the mouth until into the fluid form, nothing except fluid being allowed to enter the stomach. With practice in chewing food the tongue becomes like a filter that will allow no solid substance to pass. Such chewing takes time but it is time well spent and food so chewed will go twice as far as food bolted, as it is too apt to be. Scientific observations on the value of such chewing are much needed and when made will be most valuable in the study of dietetics.

I remain, Sirs, yours faithfully,

JoHN HADDON, M.D. Edin.

Denholm, Hawick, N.B., Jan. 8th, 1905

\title{
THE L.S.A. QUALIFICATION AND MEDIC.AL APPOINTMENTS.
}

\section{To the Editors of THE LANCET.}

SIRs, - It is refreshing to find a member of the profession who is not an L.S.A. wielding his pen in favour of justice being done to the holders of this much belittled diploma in the matter of hospital appointments, \&c. That the professional equipment of the Licentiates of the Apothecaries' Society is of a satisfactory character is shown by their success in the competitive examinations for the navy and army. I have before me a table ${ }^{1}$ showing percentages of successes of holders of various degrees and diplomas at these examinations, from which I extract the following:-

L S.A. alone

Srish

Irish

" $\quad,, \quad \ldots \quad \ldots \quad 34$

Edinburgh $\quad, \quad, \quad, \quad \ldots \quad \ldots \quad 50$

Glasgow $\quad, \quad, \quad, \quad \ldots \quad \ldots 66$

Dublin

Royal University degree alone 63

These navy and army competitions are the only postgraduate tests in which all candidates appear on equal terms and the results should, I think, convince all impartial persons that the L.S.A. is not the inferior practitioner that the holders of these other degrees and diplomas often represent him to be and that he is capable of more than holding his own in professional competition. This being so, is it asking too much that the powers that be should give to the persons with this diploma proper and sufficient titles and that the ridiculous chatter about it being the lowest qualification for admittance to the Medical Register should cease? Is it not simple justice that all hospital appointments which are open to holders of Conjoint diplomas, \&c., should be equally open to the L.S.A.? Your correspondent, "Not an L.S.A.," is quite right about the surgical examiners at the Apothecaries' Society being appointed by the General Medical Council, and I may add that it is the duty of these examiners (see Medical Act, 1886, Section 5, Paragraph 2) "to secure the maintenance of such standard of proficiency in medicine, surgery, and midwifery as is required under the foregoing provisions of this Act." The effect of this clause is that every final examination for the L.S.A. is conducted under the direct supervision of the General Medical Council's own appointed examiners who are responsible for the standard of efficiency. The same conditions now apply to the L.A.H. Irel. At no other qualifying examinations, whether for degrees or diplomas, are the interests of the public so carefully safeguarded. Medical members of 